\title{
Parâmetros de qualidade físico-químicos e avaliação da atividade antioxidante de folhas de Plectranthus barbatus Andr. (Lamiaceae) submetidas a diferentes processos de secagem
}

SILVA, C.F.G.'; MENDES, M.P.1; ALMEIDA, V.V.'; MICHELS, R.N.2; SAKANAKA, L.S.2; TONIN, L.T.D.1* Universidade Tecnológica Federal do Paraná, UTFPR. R. Marcílio Dias, 635, Apucarana, PR, CEP 86812-460. ¿Universidade Tecnológica Federal do Paraná, UTFPR. Av. dos Pioneiros, 3131, Londrina, PR, CEP 86036-370. *Autor para correspondencia: liliandusman@utfpr.edu.br

RESUMO: O presente trabalho descreve a composição físico-química, a avaliação da atividade antioxidante pelo método de sequestro de radicais livres DPPH, determinação de flavonoides e de fenóis totais dos extratos etanol, acetona e aquoso de Plectranthus barbatus Andr. (Lamiaceae), desidratadas em secador solar e em estufa de circulação de ar a $60{ }^{\circ} \mathrm{C}$. Os valores de atividade de água encontrados para as duas secagens foram inferiores ao mínimo necessário para o crescimento e produção de toxina de patógenos de importância alimentar. Os resultados das análises físico-químicas demonstraram que ambos os processos mostraram-se eficientes na desidratação de $P$. barbatus. Os resultados demonstraram que os extratos acetona (estufa) e etanol (estufa e secador solar) foram os que apresentaram maior conteúdo de fenóis totais. O extrato etanólico (estufa) apresentou maior quantidade de flavonoides e melhor potencial antioxidante $\left(\mathrm{IC}_{50}=75,71 \pm 10,57 \mu \mathrm{g} \mathrm{mL}-1\right)$.

Palavras-chave: Boldo; Coleus barbatus; atividade antioxidante; secagem.

\begin{abstract}
Quality of the leaves of Plectranthus barbatus Andr. (Lamiaceae) dried in solar dryer and oven. This paper describes the physicochemical composition, the evaluation of the antioxidant activity by free DPPH radicals using the scavenging method, the determination of flavonoids and total phenolic compounds of ethanol, acetone and aqueous extracts of the medicinal plant Plectranthus barbatus Andr. (Lamiaceae), dehydrated in solar dryer and circulation oven at $60^{\circ} \mathrm{C}$. Water activity rates for two drying methods were below the minimum necessary for growth and toxin production of important food pathogens. Physicochemical results showed that both processes were effective in the dehydration of $P$. barbatus. The results demonstrated that the acetone (over) and ethanol (over and solar dryer) extracts showed the highest content of total phenols. The ethanol extract (over) showed the highest amount of flavonoids and better antioxidant activity $(75.71 \pm 10.57 \mu \mathrm{g} \mathrm{L}-1)$.
\end{abstract}

Keywords: Boldo; Coleus barbatus; antioxidant activity; drying.

\section{INTRODUÇÃO}

A espécie Plectranthus barbatus Andrews pertence à família Lamiaceae (sin. Labiatae) popularmente conhecida como "falso boldo" ou "boldo brasileiro". Possui um grande número de sinonímias: Coleus barbatus Benth, Plectranthus forskohlii Briq, Plectranthus forskalaei Willd, Plectranthus kilimandschari (Gürke) H.L. Maass., Plectranthus grandis (Cramer) R.H. Willemse, Coleus kilimandschari Gürke ex Engl, Coleus comosus A. Rich, Coleus coerulscens Gürke e Coleus forskohlii Briq. (Pulliah, 2006). É utilizada na medicina popular para tratar distúrbios do sistema digestivo e nervoso, doenças hepáticas e dentárias (Lukhoba et al., 2006). Outros estudos reportaram sua atividade anti-inflamatória, antifúngica, antibacteriana (Kapewangolo et al., 2013; Matu \& Van Staden, 2003), antioxidante, inibição de enzimas do HIV-1 (Kapewangolo et al., 2013; Maioli et al., 2010; Tamasiro et al., 1998), citotóxica (Costa \& Nascimento, 2003), redução da gordura total do sangue (Badmaev et al., 2015), e no tratamento de asmas, bronquites, pneumonias e outras doenças respiratórias (Lukhoba et al., 2006; Yang et al., 2006). Seu estudo fitoquímico revelou a presença 
de diversos diterpenos (Albuquerque et al., 2007; Bhat et al., 1977; Kelecom, 1984; Kelecom et al., 1987; Tandon et al., 1977; Wang et al., 1973; Zelnik et al., 1977), além de derivados fenólicos, tais como nepetoidinas A e B (Grayer et al., 2003) e o ácido rosmarínico (Falé et al., 2009). Estudos mais recentes têm reportado seu uso como um ingrediente de alimentos funcionais e suplementos alimentares para perda e controle de peso, tendo a forskolina como principal componente (Henderson et al., 2005; Kamohara \& Noparatanawong, 2013; Kamohara et al., 2015). A espécie faz parte da Relação Nacional de Plantas Medicinais de Interesse ao SUS (Renisus, 2015), constituída de espécies vegetais com potencial de avançar nas etapas da cadeia produtiva e de gerar produtos de interesse do Ministério da Saúde do Brasil.

Os antioxidantes podem ser definidos como substâncias capazes de retardar ou inibir a oxidação de substratos oxidáveis, podendo ser enzimático ou não enzimático, tais como que $\alpha$-tocoferol (vitamina E), $\beta$-caroteno, ácido ascórbico (vitamina C) e os compostos fenólicos (Halliwell \& Gutteridge, 2007). Quando ocorre aumento das espécies reativas de carbono, enxofre, nitrogênio e oxigênio produzidas pelo nosso organismo e/ou decréscimo da atividade antioxidante celular, o estresse oxidativo é gerado, podendo lesar diferentes moléculas. $O$ estresse oxidativo está associado a inúmeras doenças, entre elas: diabetes, doença de Parkinson e de Alzheimer, esclerose múltipla, distrofia muscular, catarata e retinopatias, aterosclerose, infarto do miocárdio, cirrose hepática e vários tipos de câncer (Godon et al., 1998; Halliwell \& Gutteridge, 2007). O consumo de antioxidantes naturais, como os compostos fenólicos presentes na maioria das frutas e plantas que inibem a formação de radicais livres, tem sido associado a uma menor incidência de doenças relacionadas com o estresse oxidativo (Droge, 2002). Além disso, a substituição dos antioxidantes sintéticos pelos naturais para retardar a peroxidação lipídica em alimentos tem sido investigada, visto que estudos em animais evidenciaram que a exposição aguda e prolongada aos antioxidantes sintéticos levou ao desenvolvimento de diversas doenças (Ito et al., 1982).

Diferentes tipos de solventes têm sido utilizados para extrair compostos com propriedades antioxidantes das plantas. Misturas aquosas de etanol, metanol e acetona são comuns (Sun \& Ho, 2005). O tipo e a polaridade do solvente podem afetar a transferência de elétrons e de átomos de hidrogênio, que é aspecto-chave na medida do potencial antioxidante. A presença de compostos não antioxidantes nas soluções testadas também pode afetar os resultados (Pérez-Jiménez \& SauraCalixto, 2006).
A composição química das frutas e plantas depende de vários fatores, como solo, clima e processamento pós-colheita aos quais são submetidas. Neste último quesito, o que mais interfere no teor e na manutenção desta composição é a secagem (Corrêa Junior et al., 2006). A secagem retira a água livre presente nos tecidos vegetais, impedindo que ocorra degradação enzimática, mantendo a qualidade do material. Além disso, a redução da quantidade de água aumenta a quantidade de princípios ativos em relação à massa seca (Hii et al., 2012). As plantas medicinais são sensíveis ao processo de secagem e as temperaturas a que são submetidas podem causar alterações na quantidade e qualidade dos princípios ativos, porém no geral, temperaturas entre $40^{\circ} \mathrm{C}$ e $60^{\circ} \mathrm{C}$ são as mais indicadas independentes do método de secagem (Melo et al., 2004).

A utilização da energia solar para a secagem de alimentos constitui uma boa alternativa para a elaboração de alimentos com qualidade e baixo custo, além de ser uma fonte de energia ecologicamente correta (Patrocinio \& Murakami Iha, 2010). O uso de secadores solares pode ser utilizado como uma forma de minimizar a presença de fontes contaminantes, podendo atingir a temperatura de $70^{\circ} \mathrm{C}$, suficiente para secar os alimentos e eliminar microrganismos patogênicos (Oetterer et al., 2006).

$\mathrm{O}$ presente trabalho teve como objetivo verificar a possível influência do método de secagem nas propriedades físico-químicas, atividade antioxidante, conteúdo de compostos fenólicos totais e flavonoides das folhas de $P$. barbatus, bem como a atuação do solvente extrator para as três últimas propriedades.

\section{MATERIAL E MÉTODO \\ Coleta do material vegetal}

As folhas de P. barbatus Andr. ("falso boldo" ou "boldo brasileiro"), pertencente à família Lamiaceae, foram coletadas em Londrina, Paraná, Brasil em Março de 2012. Uma exsicata está depositada sob o número UNIFIL-2426, no herbário do Centro Universitário Filadélfia (UniFil).

\section{Secagem do material vegetal}

As folhas foram secas em estufa de circulação de ar e secador solar, até a verificação de massa constante das amostras. Em estufa a temperatura de secagem foi $60^{\circ} \mathrm{C}$. Em secador solar, a temperatura interna variou de $36,6^{\circ} \mathrm{C}$ a $58,6^{\circ} \mathrm{C}$. Foi monitorada ainda, a temperatura externa ao secador e a umidade relativa do ar. A perda de massa das folhas de $P$. barbatus foi monitorada a cada 15 minutos. 


\section{Secador solar}

O secador solar empregado neste estudo foi constituído por uma caixa de madeira com laminado de cor escura, por absorver mais calor, e uma grade feita com material de aço inox, devido à resistência a corrosão. A grade foi fixada ao centro da caixa, onde foram distribuídas as folhas de $P$. barbatus. Na parte superior do secador havia uma lamina de vidro móvel, que facilitava o manuseio das folhas e aprisionava o calor dentro do secador.

\section{Determinação da atividade de água e propriedades físico-químicas}

A atividade de água foi analisada, a $25^{\circ} \mathrm{C}$, em aparelho AquaLab Dew Point Water Activity Meter 4TE. O teor de umidade e cinzas das amostras foi determinado conforme o método descrito pela AOAC (1998), e o teor de proteína bruta segundo o método Kjedahl utilizando o fator de correção igual a 6,25 (Instituto Adolfo Lutz, 2008). Os lipídios totais foram extraídos com uma mistura de clorofórmio e metanol (1:2 v/v) segundo Bligh \& Dyer (1959). Os carboidratos foram calculados pela diferença: $100-(\%$ umidade $+\%$ cinzas $+\%$ proteína bruta + $\%$ lipídios totais). Todas as análises físico-químicas foram procedidas em triplicata.

\section{Preparação dos extratos}

As folhas secas de $P$. barbatus foram exaustivamente extraídas por maceração em etanol P.A. e acetona P.A. à temperatura ambiente até completo esgotamento. Após evaporação total do solvente em rota-evaporador, à temperatura de 40 -C foram obtidos os extratos etanólico e acetona. Os extratos aquosos foram preparados, por infusão, usando-se $1,0 \mathrm{~g}$ das folhas secas em $100 \mathrm{~mL}$ de água destilada (equivalente a uma xícara de chá) a aproximadamente $100{ }^{\circ} \mathrm{C}$ por 10 minutos, em recipiente coberto com vidro relógio. As amostras foram filtradas e estocadas sob refrigeração por até 24 horas. O tempo de infusão e a temperatura usada neste trabalho têm sido descrito por vários autores como condições eficientes para extrair compostos fenólicos de plantas (Katalinic et al., 2006; Lima et al., 2004; Sue et al., 2006).

\section{Determinação do teor de fenólicos totais}

O teor de fenólicos totais dos extratos etanólico, acetona e aquoso foi determinado pelo método espectrofotométrico (UV-VIS, Lambda 750, Perkin Elmer), utilizando o reagente Folin-Ciocalteu (Singleton \& Rossi, 1965) e curva padrão de ácido gálico $(y=0,0119 x+0,0205)$. Os resultados foram expressos em mg equivalente de ácido gálico por grama do extrato e por grama da planta seca (mg EAG $\mathrm{g}^{-1}$ ). Todas as determinações foram realizadas em triplicata.

\section{Determinação do teor de flavonoides}

O doseamento de flavonoides foi realizado segundo metodologia descrita por Peixoto Sobrinho et al. (2010) com adaptações. Foram preparadas soluções de concentração $1000 \mu \mathrm{g} \mathrm{mL}^{-1}$ dos extratos orgânicos e $10000 \mu \mathrm{g} \mathrm{mL}-1$ dos extratos aquosos. Foram transferidos $1,0 \mathrm{~mL}$ destas soluções para balões volumétricos de $10 \mathrm{~mL}$, ao qual foram acrescentados $0,24 \mathrm{~mL}$ de ácido acético glacial, 4,0 $\mathrm{mL}$ de solução aquosa de piridina a $20 \%$ e $1,0 \mathrm{~mL}$ do reagente de cloreto de alumínio em metanol $(50 \mathrm{mg}$ $\mathrm{mL}^{-1}$ ), completando-se o volume com água destilada. Após 30 minutos as leituras foram realizadas a 420 nm em espectrofotômetro (UV-VIS, Lambda 750, Perkin Elmer). Antes da leitura de cada extrato, o aparelho foi zerado com solução contendo todos os reagentes menos a solução de cloreto de alumínio. Para a construção da curva de calibração, foi preparado uma solução metanólica de rutina a 0,5 $\mathrm{mg} \mathrm{mL}^{-1}$. Desta solução foram retiradas 6 alíquotas para balões volumétricos de $10 \mathrm{~mL}$ e adicionadas em cada balão as mesmas quantidades de ácido acético glacial, solução aquosa de piridina e cloreto de alumínio em metanol, completando-se o volume com água destilada. Após 30 minutos as leituras foram realizadas a $420 \mathrm{~nm}$. Os resultados foram expressos em mg de rutina por grama de extrato e em porcentagem.

\section{Determinação do potencial antioxidante}

A capacidade de sequestro de radicais livres dos extratos etanólico, acetona e aquoso de $P$. barbatus foi determinada, utilizando o método da capacidade de sequestrar o radical livre 1,1-difenil-2picril-hidrazila (DPPH), descrito por Brand-Williamns et al. (1995) com pequenas modificações. Foram preparadas várias concentrações dos extratos e do padrão BHT (butil hidroxitolueno) em metanol. Uma alíquota de $1,0 \mathrm{~mL}$ das amostras testadas foram misturadas com 2,0 mL de uma solução de $40 \mu \mathrm{g}$ $\mathrm{mL}^{-1}$ de DPPH em metanol. A mistura foi agitada e após 30 minutos de incubação, a absorbância foi determinada em espectrofotômetro (UV-VIS, Lambda 750, Perkin Elmer) a $515 \mathrm{~nm}$. A atividade antioxidante foi expressa como porcentagem de inibição em relação ao controle (DPPH sem antioxidante) de acordo com a equação (Yen \& Duh, 1994):

sequestro $\mathrm{DPPH}=\%$ Inibição $=\left[\left(\mathrm{A}_{0}-\mathrm{A}\right) / \mathrm{A}_{0}\right] \times 100$ $A_{0}=$ absorbância do DPPH sem antioxidante (solvente extrator + solução DPPH)

A = absorbância da amostra em DPPH após 30 minutos de reação

A determinação da $I C_{50}$, ou seja, a concentração da amostra ou padrão que causa 
$50 \%$ de inibição da concentração inicial de DPPH foi obtida por regressão linear dos pontos plotados graficamente (concentração versus porcentagem de inibição). Todas as determinações foram realizadas em triplicata.

\section{Análise estatística}

Os resultados apresentados neste estudo correspondem à média de três repetições \pm desvio padrão da média. Foram considerados estatisticamente diferentes os resultados que apresentaram probabilidade de ocorrência da hipótese de nulidade menor que $5 \% \quad(p<0.05)$ aplicando-se ANOVA, seguido de comparações múltiplas pelo teste de Tukey. As análises estatísticas foram realizadas utilizando-se o software Statistica versão 8.0 .

\section{RESULTADO E DISCUSSÃO}

$\mathrm{Na}$ Figura 1 são apresentadas as curvas de secagem obtidas para $P$. barbatus submetido à secagem em estufa e em secador solar, verificandose que ambos os processos apresentam dinâmicas de secagem semelhantes, no que diz respeito à perda significativa de massa logo no início do processo de secagem, tornando-se menos significativa com o tempo. O tempo de secagem foi determinado a partir do ponto que a perda de massa tornou-se praticamente constante, sendo que a secagem em estufa foi de 4,5 horas em
TABELA 1. Temperatura ambiente (TA), umidade relativa (UR) e temperatura interna do secador solar ( $\mathrm{TI})$ monitoradas as cada 15 minutos, durante o processo de secagem de $P$. barbatus em secador solar

\begin{tabular}{llll}
\hline Tempo $(\mathrm{min})$ & $\mathrm{TA}\left({ }^{\circ} \mathrm{C}\right)$ & $\mathrm{UR}(\%)$ & $\mathrm{TI}\left({ }^{\circ} \mathrm{C}\right)$ \\
\hline 0 & 31,3 & 28 & 36,6 \\
15 & 33,5 & 18 & 40,3 \\
30 & 33,1 & 17 & 43,8 \\
45 & 33,4 & 16 & 46,6 \\
60 & 32,7 & 16 & 53,5 \\
75 & 32,0 & 16 & 54,9 \\
90 & 32,0 & 16 & 55,0 \\
105 & 31,5 & 16 & 58,6 \\
120 & 30,2 & 17 & 58,4 \\
\hline
\end{tabular}

uma temperatura constante de $60{ }^{\circ} \mathrm{C}$, enquanto no secador solar as folhas permaneceram por 2 horas e a temperatura variou de 36,6 à 58,6 •C.

$\mathrm{Na}$ Tabela 1 estão apresentados os dados de monitoramento da temperatura ambiente, umidade relativa do ar e de temperatura no interior do secador solar, durante o processo de secagem do boldo.

Os resultados de atividade de água, apresentados na Tabela 2, revelam que houve diferenças significativas $(p<0,05)$ entre os dois processos de secagem. A amostra submetida à secagem em estufa apresentou menor atividade de

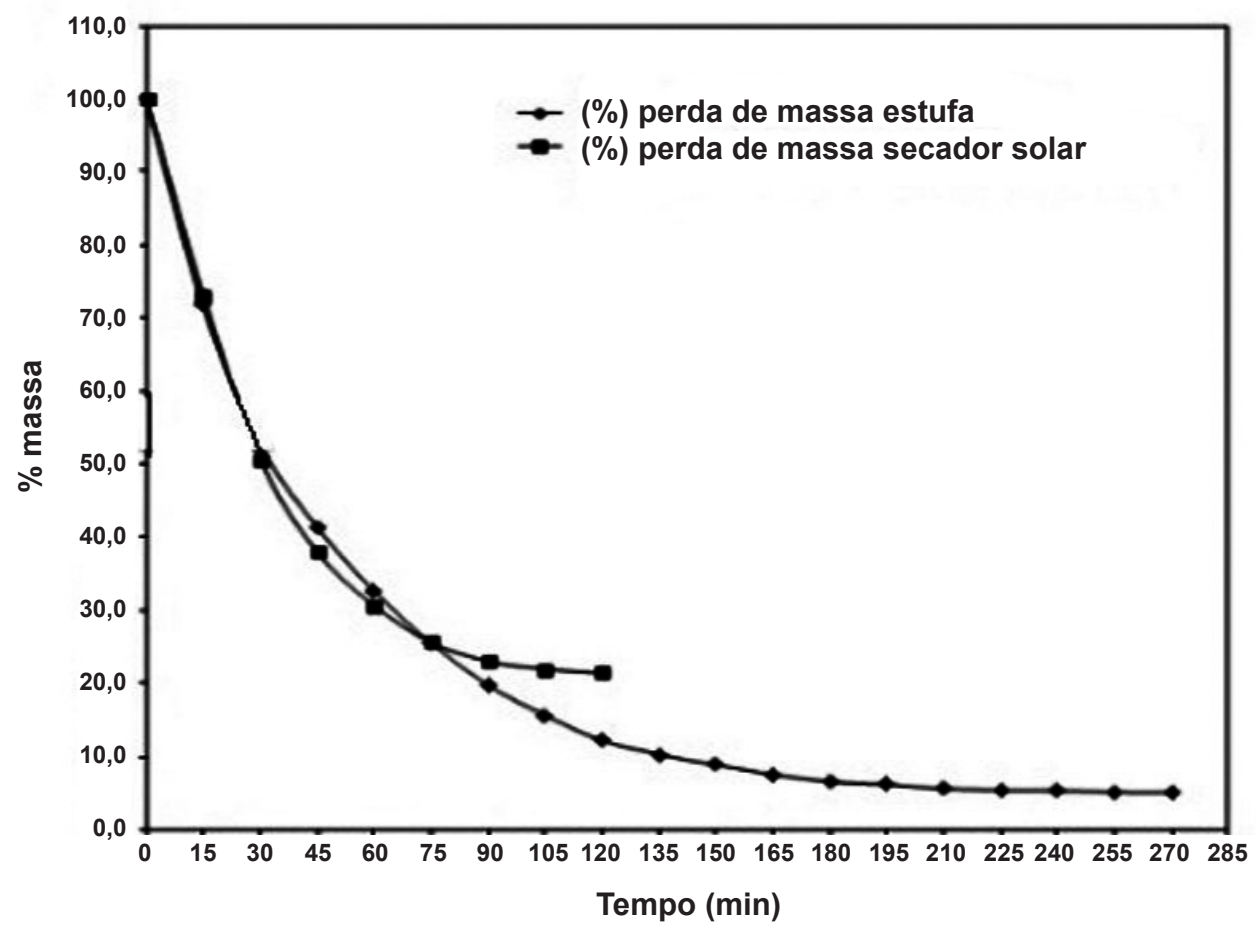

FIGURA 1. Curvas de secagem para $P$. barbatus desidratado em estufa $\left(60^{\circ} \mathrm{C}\right)$ e em secador solar (variação de temperatura). 
TABELA 2. Resultados das análises de atividade de água de $P$. barbatus submetido a dois processos de secagem

\begin{tabular}{ccc}
\hline Secagem & $\begin{array}{c}\text { Atividade } \\
\text { de água }\end{array}$ & $\begin{array}{c}\text { Temperatura } \\
\left({ }^{\circ} \mathrm{C}\right)\end{array}$ \\
\hline Estufa & $0,324 \pm 0,010^{\mathrm{b}}$ & 25,03 \\
Secador Solar & $0,570 \pm 0,022^{\mathrm{a}}$ & 25,11 \\
\hline
\end{tabular}

Resultados expressos como média \pm desvio padrão $(n=3)$. Letras diferentes na mesma coluna indicam diferenças significativas $(p<0,05)$ pelo teste de Tukey.

água que aquela submetida à secagem em secador solar. Os valores de atividade de água encontrados para $P$. barbatus, contudo, são inferiores ao mínimo necessário para o crescimento e produção de toxina de patógenos de importância alimentar. Segundo Beauchat (1981), o limite mínino de atividade de água para o crescimento dos micro-organismos é de $0,60 a_{w}$ enquanto, para a produção de toxinas, 0 limite é de $0,83 \mathrm{a}_{\mathrm{w}}$.

Nos resultados das análises físico-químicos realizadas para $P$. barbatus (Tabela 3 ), observaram-se diferenças significativas $(p<0,05)$ entre as amostras submetidas aos dois processos de secagem, no que se refere ao teor de umidade, teor de lipídios totais e de carboidratos. O boldo desidratado em secador

TABELA 3. Resultados das análises físico-químicas de $P$. barbatus submetido a dois processos de secagem

\begin{tabular}{lcc}
\hline Análise & $\begin{array}{c}\text { Estufa } \\
(\% \mathrm{~m} / \mathrm{m})\end{array}$ & $\begin{array}{c}\text { Secador Solar } \\
(\% \mathrm{~m} / \mathrm{m})\end{array}$ \\
\hline Umidade & $6,64 \pm 0,12^{\mathrm{b}}$ & $9,53 \pm 0,15^{\mathrm{a}}$ \\
Cinzas & $9,47 \pm 0,33^{\mathrm{a}}$ & $9,06 \pm 0,08^{\mathrm{a}}$ \\
Proteínas & $14,40 \pm 2,35^{\mathrm{a}}$ & $16,62 \pm 0,62^{\mathrm{a}}$ \\
Lipídios & $11,93 \pm 1,68^{\mathrm{b}}$ & $16,26 \pm 1,38^{\mathrm{a}}$ \\
Carboidratos & $57,56 \pm 2,11^{\mathrm{a}}$ & $48,53 \pm 2,04^{\mathrm{b}}$ \\
\hline
\end{tabular}

Resultados expressos como média \pm desvio padrão $(n=3)$. Letras iguais na mesma linha indicam que não há diferenças significativas $(p<0,05)$ pelo teste de Tukey. solar apresentou o maior percentual em umidade, possivelmente decorrente de uma menor eficiência no processo de desidratação, o que poderia ser melhorado deixando as folhas no secador por um período de tempo maior do que duas horas. O teor de lipídios foi superior para o boldo desidratado em secador solar, enquanto que o teor de carboidratos foi superior para o boldo desidratado em estufa. Os resultados demonstram que ambos os processos de secagem são eficientes na desidratação de $P$. barbatus quando analisadas suas propriedades físico-químicas.

O teor de cinzas, que representam os minerais contidos nos alimentos, encontrado para $P$. barbatus foi superior ao reportado por Borges et al. (2012) para espécies da mesma família: Ocinum gratissimum - alfavaca $(8,12 \%)$, Origanum vulgaris - orégano $(6,36 \%)$ e Thymus vulgaris - tomilho $(6,33 \%)$ e próximo ao valor máximo relatado para verduras, hortaliças e derivados na TACO (NEPAUNICAMP, 2012), que é de $10,20 \%$ para as folhas de coentro desidratadas.

A identificação de espécies vegetais ricas em proteínas e incentivos de cultivo e consumo destas espécies podem contribuir para diminuir as deficiências nutricionais de populações de baixo poder aquisitivo, que têm acesso limitado a proteínas animais, além de fornecer alternativas nutricionais para a população em geral (Aletor \& Adeogum, 1995). Os valores de proteínas encontrados para a espécie de boldo em estudo foram superiores aqueles reportados por Kinupp \& Barros (2008) para as espécies da mesma família: Salvia guaranitica $(6,9 \%)$ e Vitex megapotamica $(2,07 \%)$ e similares aqueles reportados por Borges et al. (2012) para a alfavaca $(17,37 \%)$, orégano $(13,36 \%)$ e tomilho $(15,54 \%)$, podendo esta ser considerada uma boa fonte de proteína vegetal, estando acima do valor médio relatado pela TACO (NEPA-UNICAMP, 2012), que é de $9,70 \%$.

Os valores de lipídios encontrados neste trabalho $(11,93 \%$ para boldo seco em estufa e $16,26 \%$ para boldo seco em secador solar) foram

TABELA 4. Conteúdo de fenóis totais (FT), flavonoides (FLV) e atividade antioxidante $\left(\mathrm{IC}_{50}\right)$ de $P$. barbatus submetido a dois processos de secagem

\begin{tabular}{|c|c|c|c|c|c|}
\hline Solvente extrator & Secagem & FT (mg EAG g $\left.{ }^{-1}\right)$ & FLV (mg rutina $\left.\mathbf{g}^{-1}\right)$ & FLV (\%) & $\mathrm{IC}_{50}(\mu \mathrm{g} \mathrm{mL}-1)$ \\
\hline Acetona & Estufa & $1053,08 \pm 22,32^{a}$ & $10,89 \pm 1,49 c$ & 1,09 & $318,83 \pm 21,02^{a}$ \\
\hline Etanol & Estufa & $920,59 \pm 46,17 \mathrm{~b}$ & $66,75 \pm 0,63^{a}$ & 6,67 & $75,71 \pm 10,57$ \\
\hline Aquoso & Estufa & $737,12 \pm 3,50$ & $1,14 \pm 0,18^{d}$ & 0,11 & $198,14 \pm 5,45^{b}$ \\
\hline Acetona & Secador Solar & $1017,23 \pm 6,72^{a}$ & $9,46 \pm 1,41^{c}$ & 0,95 & $235,58 \pm 25,29 b$ \\
\hline Etanol & Secador Solar & $1030,95 \pm 5,40 a$ & $26,05 \pm 1,27 \mathrm{~b}$ & 2,60 & $133,44 \pm 6,32^{c}$ \\
\hline Aquoso & Secador Solar & $736,84 \pm 1,75^{c}$ & $1,21 \pm 0,26{ }^{d}$ & 0,12 & $288,04 \pm 15,63^{a}$ \\
\hline $\mathrm{BHT}^{*}$ & - & - & - & - & $20,89 \pm 0,69$ \\
\hline
\end{tabular}

Resultados expressos como média \pm desvio padrão $(n=3)$. Letras iguais na mesma coluna indicam que não há diferenças significativas $(p<0,05)$ pelo teste de Tukey. 'BHT - butil hidroxitolueno - antioxidante sintético. 
superiores aqueles relatados por Borges et al. (2012) para espécies da mesma família: alfavaca $(2,80 \%)$, orégano $(6,40 \%)$ e tomilho $(9,30 \%)$.

Os valores de fenóis totais, flavonoides e atividade antioxidante, expresso em $\mathrm{IC}_{50}$, para os extratos acetona, etanólico e aquoso estão apresentados na Tabela 4.

Os polifenóis atuam como sequestradores de radicais livres e têm despertado grandes interesses por possuírem a propriedade de impedir ou minimizar o estresse oxidativo causados pelos radicais livres (Morais et al., 2009). Os resultados obtidos para a determinação de fenólicos totais pelo método Folin-Ciocalteu, para $P$. barbatus, demonstrou que o tipo de secagem interferiu na quantidade de fenóis totais do extrato etanólico, havendo uma perda de $10,70 \%$ de compostos fenólicos quando da secagem em estufa. Esta perda pode ser resultado da ligação dos compostos fenólicos com outros componentes, tais como as proteínas, ou devido a uma alteração na estrutura química causada pela secagem (Qu et al., 2010). Nossos resultados estão de acordo com Dixon \& Paiva (1995), que sugerem que as plantas respondem a lesões, aumentando seu conteúdo de compostos fenólicos para reparar o tecido danificado. Isto pode ter sido causada pela incidência dos raios solares na secagem solar.

A solubilidade dos compostos fenólicos varia de acordo com a polaridade do solvente utilizado, o grau de polimerização dos fenólicos e suas interações com outros constituintes da planta (Naczk \& Shahidi, 2004). Os diferentes solventes de extração apresentaram diferenças significativas $(p<0,05)$ para a secagem em estufa, sendo a acetona o solvente mais eficiente na extração dos compostos fenólicos totais $(1053,08$ $\pm 22,32 \mathrm{mg} \mathrm{EAG} \mathrm{g}^{-1}$ extrato). A análise dos dados para a secagem em secador solar demonstrou que apenas o extrato aquoso $(736,84 \pm 1,75 \mathrm{mg}$ EAG $g^{-1}$ ) apresentou extração significativamente menor do que os extratos etanólico $(1030,95 \pm$ $\left.5,40 \mathrm{mg} \mathrm{EAG} \mathrm{g}^{-1}\right)$ e de acetona $(1017,23 \pm 6,72$ mg EAG $\mathrm{g}^{-1}$ ), os quais apresentaram eficiência de extração significativamente semelhante. $\mathrm{O}$ extrato aquoso foi o menos eficiente na extração dos compostos fenólicos para ambas as secagens, não apresentando diferença significativa entre a estufa $\left(737,12 \pm 3,50 \mathrm{mg} \mathrm{EAG} \mathrm{g}^{-1}\right)$ e o secador solar $(736,84$ $\left.\pm 1,75 \mathrm{mg} \mathrm{EAG} \mathrm{g}^{-1}\right)$.

O método espectrofotométrico utilizado para determinação de fenóis totais, não é um método específico, pois detecta todos os grupos fenólicos presentes no extrato, incluindo proteínas extraíveis, além de reduzir substâncias como o ácido ascórbico (Naczk \& Shahidi, 2004). Levando-se em conta esta informação, determinou-se o teor de flavonoides presentes nos extratos preparados. A estrutura dos flavonoides garante a estes compostos alta atividade antioxidante (Rice-Evans et al., 1996). O teor de flavonoides apontou diferenças significativas $(p<0,05)$ quando comparado os solventes extratores utilizados em um mesmo tipo de secagem, indicando o etanol como o solvente mais eficiente para ambos os sistemas de secagem $\left(66,75 \pm 0,63 \mathrm{mg} \mathrm{g}^{-1}\right.$ para secagem em estufa e 26,05 $\pm 1,27 \mathrm{mg} \mathrm{g}^{-1}$ para secagem em secador solar). Observa-se ainda, que o extrato etanólico proveniente das folhas de boldo secas em estufa apresentou um percentual $61,0 \%$ maior de flavonoides quando comparado com o extrato etanólico proveniente das mesmas folhas secas em secador solar, sugerindo que o tipo de secagem aplicado no processo exerce grande influência no rendimento final dos compostos presentes nesta planta.

Os testes para verificar as propriedades antioxidantes nas plantas são importantes para descobrir novas e promissoras fontes de antioxidantes naturais, alimentos funcionais e/ou com propriedades farmacêuticas. O método para determinar o potencial antioxidante utilizado neste trabalho, foi o do sequestro do radical livre DPPH. O teste consiste na redução do radical DPPH, púrpura, que, ao receber um elétron ou um radical hidrogênio muda sua coloração para amarelo, por tornar-se estável, e o desaparecimento da absorção pode ser avaliado pelo decréscimo da absorbância. Quanto menor o valor de $\mathrm{IC}_{50}$ apresentado pela amostra, maior é sua atividade antioxidante, pois será necessária uma quantidade menor da planta para reduzir $50 \%$ do radical livre $\mathrm{DPPH}$.

A análise dos resultados de atividade antioxidante para $P$. barbatus, expressos em $I_{50}$, demonstrou que os diferentes métodos de extração apresentaram diferenças significativas $(p<0,05)$ para os dois tipos de secagem. O extrato etanólico apresentou melhor atividade antioxidante para os dois tipos de secagens, seja em estufa $(75,71 \pm$ $\left.10,57 \mu \mathrm{g} \mathrm{mL}^{-1}\right)$ ou em secador solar $(133,44 \pm 6,32$ $\mu \mathrm{g} \mathrm{mL}-1$ ), demonstrando sua melhor capacidade de extrair componentes bioativos, merecendo estudos mais avançados nesse sentido.

O tipo de secagem forneceu diferentes resultados para a atividade antioxidante para todos os extratos, sendo que a secagem em estufa ofereceu melhores resultados, demonstrando a influência negativa da incidência solar na preservação dos compostos antioxidantes do boldo. Nossos resultados estão de acordo com diversos autores que relataram a influência da temperatura de secagem na atividade antioxidante, como por exemplo, os estudos das folhas de Musa acuminata (Sagrin \& Chong, 2013) e do fruto Solanum muricatum Ait (Di Scala et al., 2011). Hossain et al. (2010) relataram

Rev. Bras. PI. Med., Campinas, v.18, n.1, p.48-56, 2016. 
que as folhas secas por congelamento de plantas da família Lamiaceae forneceram extratos com menor potencial antioxidante que àquelas secas à temperatura ambiente. Os valores mais elevados de antioxidantes podem estar associados com a indução de mecanismos antioxidantes nestas ervas em resposta ao stress no início do processo.

$O$ valor de $\mathrm{IC}_{50}$ do extrato etanólico (desidratado em estufa) foi apenas 3,6 vezes maior que a do antioxidante sintético BHT, demonstrando que o bom poder antioxidante desta planta pode ser explicado pela presença de substâncias capazes de inibir os radicais livres. Os flavonoides e outros compostos fenólicos presentes em plantas superiores são conhecidos por apresentarem potencial efeito antioxidante (Oh et al., 2001; Lima et al., 2006). Pode-se observar que o extrato que apresentou maior quantidade de flavonoides foi aquele que apresentou maior potencial antioxidante, sugerindo que a presença destes compostos pode influenciar diretamente nesta atividade. $O$ valor de $\mathrm{IC}_{50}$ de $75,71 \pm 10,57 \mu \mathrm{g} \mathrm{mL}-1$ obtido neste trabalho foi cinco vezes maior que o reportado por Kapewangolo et al. (2013) e duas vezes maior que o reportado por Maioli et al. (2010) para a mesma espécie. Estas diferenças nos resultados de atividade antioxidante podem ser influenciadas por diversos fatores, tais como práticas de cultivo, origem geográfica, estágio de crescimento, condições de colheita e processamento pós-colheita (Kim et al., 2003).

Assim, conclui-se que para se obter o extrato com maior propriedade antioxidante deverse-á levar em conta o tipo de solvente e o método de secagem das folhas do boldo. Assim, no presente estudo, o etanol apresentou-se como o solvente mais indicado para a extratabilidade de compostos antioxidantes e o método de desidratação mais indicado foi a secagem em estufa à temperatura constante de $60{ }^{\circ} \mathrm{C}$. Ambos os processos de secagem foram eficientes na desidratação quando analisadas suas propriedades físico-químicas e a atividade de água. Nossos estudos colaboram para desenvolver formulações do boldo que levem a uma melhor utilização da sua biomassa, sendo este o primeiro relato referente às suas propriedades físico-químicas.

\section{AGRADECIMENTO}

UTFPR - Câmpus Apucarana e Londrina.

\section{REFERÊNCIA}

ALETOR, V.A.; ADEOGUN, O.A. Nutrient and antinutrient constituents of some tropical leafy vegetables. Food Chemistry, v. 53, p. 375-379, 1995.
ALBUQUERQUE, R.L.de et al., Diterpenos tipo abietano isolados de Plechtranthus barbatus Andrews. Química Nova, v. 30, p. 1882-1886, 2007.

AOAC - Association of Official Analytical Chemists -.Official methods of analysis of the Association of Official Analytical Chemists.16.ed. Arlington: AOAC, 1998.

BADMAEV, V. et al., Preclinical and clinical effects of Coleus forskohlii, Salacia reticulata and Sesamum indicum modifying pancreatic lipase inhibition in vitro and reducing total body fat. Journal of functional foods, v. 15, p. 44-51, 2015.

BEAUCHAT, L.R. Microbial stability as affected by water activity. Cereal Food World, v. 26, p. 345-349, 1981.

BHAT, S.V. et al., Structures and stereochemistry of new labdane diterpenoids from Coleus forskohlii Briq. Tetrahedron Letters, v. 19, p. 1669-1672, 1977.

BLIGH, F.G.; DYER, W.J. A rapid method of total lipid extraction and purification. Canadian Journal Biochemistry and Physiology, v. 37, p. 911-917, 1959.

BORGES, A.M. et al., Determinação de óleos essenciais de alfavaca (Ocimum gratissimum L.), orégano (Origanum vulgare L.) e tomilho (Thymus vulgaris L.). Revista Brasileira de Plantas Medicinais, v. 14, p. 656-665, 2012.

BRAND-WILLIAMNS, W. et al., Use of a free radical method to evaluate antioxidant activity. Lebensin Wiss Technology, v. 28, p. 25-30, 1995.

CORRÊA JUNIOR, C.; SCHEFFER, M.C.; MING, L.C. Cultivo agro-ecológico de plantas medicinais, aromáticas e condimentares. Brasília: Ministério do Desenvolvimento Agrário, 2006. 76p.

COSTA, M.C.C.D.; NASCIMENTO, S.C. Atividade citotóxica de Plectranthus barbatus Andr. (Lamiaceae). Acta Farmacéutica Bonaerense, v. 22, p. 155-158, 2003.

DI SCALA, K. et al., Changes of quality characteristics of pepino fruit (Solanum muricatum Ait) during convective drying. International Journal of Food Science \& Technology, v. 46, p. 746-753, 2011.

DIXON, R.A.; PAIVA, N.L. Stress-induced phenylpropanoid metabolism. Plant cell, v. 7, p. 1085-1097, 1995.

DROGE, W. Free radicals in the physiological control of cell function. Physiological Reviews, v. 82, p. 47-95, 2002.

FALÉ, P.L. et al., Rosmarinic acid, scutellerein 4'-methyl ether 7-O-glucuronide and (16S)-coleon $\mathrm{E}$ are the main compounds responsible for the antiacetylcholinesterase and antioxidant activity in herbal tea of Plectranthus barbatus ("falso boldo"). Food Chemistry, v. 114, p. 789-805, 2009.

GODON, C. et al., The $\mathrm{H}_{2} \mathrm{O}_{2}$ stimulation in Saccharomyces cerevisiae. The Journal of Biological Chemistry, v. 34, p. 22480-22489, 1998.

GRAYER, R.J. et al., The chemotaxonomic significance of two bioactive caffeic acid esters, nepetoidins $A$ and $\mathrm{B}$, in the Lamiaceae. Phytochemistry, v. 64, p. 519528, 2003.

HALLIWELL, B.; GUTTERIDGE, J.M.C. Free radicals in biology and medicine. 4.ed. Oxford University Press: Oxford, 2007. 851p.

HENDERSON, S. et al. Effects of Coleus forskohlii supplementation on body composition and hematological profiles in mildly overweight women. Journal of the

Rev. Bras. PI. Med., Campinas, v.18, n.1, p.48-56, 2016. 
International Society of Sports Nutrition, v. 2, p. 54-62, 2005.

HII, C.L; JANGAM, S.V.; ONGAND, S.P.; MUJUMDAR, A.S. Solar Drying: Fundamentals, Applications and Innovations. Singapore: National University of Singapore Press; 2012. 150p.

HOSSAIN, M.B. et al., Effect of drying method on the antioxidant capacity of six Lamiaceae herbs. Food Chemistry, v. 123, p. 85-91, 2010.

Instituto Adolfo Lutz. Métodos químicos e físicos para análise de alimentos. 4ed. São Paulo: IMESP, 2008. $1020 p$.

ITO, N. et al., Induction of squamous cell carcinoma in the forestomach of F344 rats treated with butylatedhydroxyanisole. Gann Japanese Journal of Cancer Research, v. 73, p. 332-334, 1982.

KAMOHARA, S.; NOPARATANAWONG, S.A. Coleus forskohlii extract improves body composition in healthy volunteers: an open-label trial. Personalized Medicine Universe, v. 2, p. 25-27, 2013.

KAMOHARA, S. et al., . Safety of a Coleus forskohlii formulation in healthy volunteers. Personalized Medicine Universe, p. 1-3, 2015.

KAPEWANGOLO, P. et al., Inhibition of HIV-1 enzymes, antioxidant and anti-inflammatory activities of Plectranthus barbatus. Journal of Ethnopharmacology, v. 149, p. 184-190, 2013.

KATALINIC, V.; et al., Screening of 70 medicinal plant extracts for antioxidant capacity and total phenols. Food Chemistry, v. 94, p. 550-557, 2006.

KELECOM, A. An abietane diterpene from the labiate Coleus barbatus. Phytochemistry, v. 23, p. 1677-1679, 1984.

KELECOM, A.; et al., Secoabietane diterpenes from Coleus barbatus. Phytochemistry, v. 26, p. 2337-2340, 1987.

KIM, D.O.; et al., Antioxidant capacity of phenolic phytochemicals from various cultivars of plums. Food Chemistry, v.81, p. 231-326, 2003.

KINUPP, V.F.; BARROS, I.B.I. Teores de proteína e minerais de espécies nativas, potenciais hortaliças e frutas. Ciência e Tecnologia de Alimentos, v. 28, p. 846-857, 2008.

LIMA, A.R.; et al., Avaliação in vitro da atividade antioxidante do extrato hidroalcoólico de folhas de bardana. Revista Brasileira de Farmacognosia, v.16, p. 531-536, 2006.

LIMA, V.L.A.G.; et al., Teor de compostos fenólicos totais em chás brasileiros. Brazilian Journal of Food Technology, v. 7, p. 187-190, 2004.

LUKHOBA, C.W.; et al., Plectranthus: a review of ethnobotanical uses. Journal of Ethnopharmacology, v. 103, p. 1-24, 2006.

MAIOLI, M.A.; et al., Iron chelating-mediated antioxidant activity of Plectranthus barbatus extract on mitochondria. Food Chemistry, v. 122, p. 203-208, 2010.

MATU, E.N.; VAN STADEN, J. Antibacterial and antiinflammatory activities of some plants used for medicinal purposes in Kenya. Journal of Ethnopharmacology, v. 87, p. 35-41, 2003.

MELO, E.C.; et al., Influência do processo de secagem na qualidade de plantas medicinais - Revisão. Engenharia na Agricultura, v. 12, p. 307-315, 2004.
MORAIS, S.M.; et al., Ação antioxidante de chás e condimentos de grande consumo no Brasil. Revista Brasileira de Farmacognosia, v 19(1B), p. 315-320, 2009.

NACZK, M.; SHAHIDI, F. Extraction and analysis of phenolics in food. Journal of Chromatography A, v. 1054 (1/2), p. 95-111, 2004.

NEPA-UNICAMP. Tabela brasileira de composição de alimentos - TACO. 4ed Revisada e Ampliada. Campinas/SP: NEPA-UNICAMP, 2011. 161p. Disponível em: http://www.unicamp.br/nepa/taco/contar/taco_4_ edicao_ampliada_e_revisada. Acesso em: 30 Jul. 2015 .

OETTERER, M.; D'ARCE, M.A.B.R.; SPOTO, M. Fundamentos de ciência e tecnologia de alimentos. 1ed. Barueri: Manole, 2006. 632p.

$\mathrm{OH}$, T.Y.; et al., Oxidative damages are critical in pathogenesis of reflux esophagitis implication of antioxidants in its treatment. Free Radical Biology \& Medicine, v. 30, p. 905-915, 2001.

PATROCINIO, A.O.T.; MURAKAMI IHA, N.Y. Em busca da sustentabilidade: células solares sensibilizadas por extratos naturais. Química Nova, v. 33, p. 574-578, 2010.

PEIXOTO SOBRINHO, T.J.S.; et al., Otimização de metodologia analítica para o doseamento de flavonoides de Bauhinia cheilantha (Bongard) Steudel. Química Nova, v. 33, p. 288-291, 2010.

PÉREZ-JIMÉNEZ, J.; SAURA-CALIXTO, F. Effect of solvent and certain food constituents on different antioxidant capacity assays. Food Research International, v. 39, p. 791-800, 2006.

PULLIAH, T. Plectranthus barbatus Andr. Encyclopaedia of World Medicinal Plants, v. 3, p. 1566-1567, 2006.

QU, W.; et al., Extraction modeling and activities of antioxidants from pomegranate marc. Journal of Food Engineering, v. 99, p. 16-23, 2010.

RENISUS - Agência Saúde. MS elabora relação de plantas medicinais de interesse ao SUS. 06/03/2009. Disponível em: < http://bvsms.saude.gov.br/bvs/sus/pdf/ marco/ms_relacao_plantas_medicinais_sus_0603.pdf $>$. Acesso em: 09 jun. 2015.

RICE-EVANS, C.A.; et al., Structure-antioxidant activity relationships of flavonoids and phenolic acids. Free Radical Biology and Medicine, v. 20, p. 933-956, 1996.

SAGRIN, M.S.; CHONG, G.H. Effects of drying temperature on the chemical and physical properties of Musa acuminate Colla (AAA Group) leaves. Industrial Crops and Products, v. 45, p. 430-434, 2013.

SINGLETON, V.L.; ROSSI, J.A.J. Colorimetry of total phenolics with phophomolybdic-phosphotungstic acid reagents. American Journal of Enology and Viticulture, v. 16, p. 144-158, 1965.

SUN, T.; HO, C. Antioxidant activities of buckwheat extracts. Food Chemistry, v. 90, p. 743-749, 2005.

SUE, X.; et al., Effects of soaking conditions on the antioxidant potentials of oolong tea. Journal of Food Composition and Analysis, v.19, p. 348-353, 2006.

TAMASIRO, V.; et al., In vitro antioxidant activity of Coleus barbatus (Andr.) Benth (false bolde) and Peumus boldo (Molina) (Boldo do Chile): a comparative study. Revista de Farmácia e Bioquímica da Universidade de São Paulo, v. 34, p. 15-17, 1998.

TANDON, J.S.; et al., Structure of coleol, a biologically

Rev. Bras. PI. Med., Campinas, v.18, n.1, p.48-56, 2016. 
active diterpene from Coleus forskohlii. Indian Journal of Chemistry, v. 15, p. 880-883, 1977.

WANG, A.H.J. et al., Structure and absolute stereochemistry of the diterpenoid Barbatusin. Journal of the American Chemical Society, v. 95, p. 598-600, 1973.

YANG, Q.R.; WU, H.Z.; WANG, X.M.; ZOU, G.A.; LIU, YW. Three new diterpenoids from Coleus forskohlii Briq. Journal Asiatic of Natural Product Research, v. 8, p.
355-360, 2006.

YEN, G.C.; DUH, P.D. Scavenging effect of methanolic extracts of peanut hulls on free-radical and activeoxygen species. Journal of Agricultural and Food Chemistry, v. 42, p. 629-632, 1994.

ZELNIK, R.; et al., Barbatusin and cyclobutatusin, two novel diterpenoids from Coleus barbatus Bentham. Tetrahedron, v. 33, p. 1457-1467, 1977. 